\title{
An Unexpected Complication Due to Metformin Use After Femur Fracture Operation: Metabolic Acidosis Without Lactic Acidosis
}

\author{
Eylem Yasar $^{1}$, Basak Altıparmak ${ }^{1}$, Semra Gümüş Demirbilek ${ }^{2}$ \\ 1. Anesthesiology, Mugla Sıtkı Kocman University, Muğla, TUR 2. Anesthesiology, Mugla Sitki Kocman \\ University, Muğla, TUR
}

$\square$ Corresponding author: Eylem Yasar, eylemtarakci@gmail.com

Disclosures can be found in Additional Information at the end of the article

\section{Abstract}

A 74-year- old male, who was known to have hypertension, chronic obstructive lung disease, and benign prostate hyperplasia, was evaluated preoperatively in our clinic for a femur fracture. In addition, it was found that the patient was using $1000 \mathrm{mg}$ of metformin per oral due to type 2 diabetes. At the preoperative cardiology evaluation, the ejection fraction was $60 \%$ with normal systolic ventricular function. Routine laboratory tests were normal. Metformin was held 24 hours before surgery. Spinal anesthesia was applied with $10 \mathrm{mg}$ bupivacaine and $20 \mathrm{mcg}$ fentanyl. Total blood loss at surgery was $150 \mathrm{cc}$. After an uneventful surgery, the patient was observed at the surgical postanesthesia care unit. Cardiac and respiratory physical examinations seemed normal but the patient had minimal acidosis and hypoxia in the arterial blood gas analysis. Twelve hours after the operation, compensated high anion gap ( $30 \mathrm{mEq} / \mathrm{l}$ ) metabolic acidosis emerged, but lactate was normal. The patient's urea and creatinine levels were normal in the control blood tests, and the patient's urine output was above 0.5 $\mathrm{ml} / \mathrm{kg}$. Within this period, glucose levels were around $80-140 \mathrm{mg} / \mathrm{dl}$. To overcome metabolic acidosis, bolus intravenous $8.4 \%$ bicarbonate solution was administered. Bicarbonate infusion was started on the continuation of metabolic acidosis and base loss despite the bolus bicarbonate treatment. Since there was no other reason for the metabolic acidosis, metformin usage was considered to cause metabolic acidosis. During this treatment period, despite high anion gap acidosis, there was no lactate elevation. The patient had normal laboratory and hemodynamic values and was discharged from the intensive care unit at postoperative Day 3.

Received 04/01/2019

Review began 04/07/2019 Review ended 04/18/2019 Published 05/02/2019

(c) Copyright 2019

Yasar et al. This is an open access article distributed under the terms of the Creative Commons Attribution License CC-BY 3.0., which permits unrestricted use, distribution, and reproduction in any medium, provided the original author and source are credited.
Categories: Anesthesiology

Keywords: metformin, methabolic acidosis, intensive care unit

\section{Introduction}

Metformin is a biguanide-derived drug commonly used in the treatment of type 2 diabetes since the 1960s. It acts by inhibiting glucose absorption from the intestine, reducing gluconeogenesis in the liver, and increasing the use of peripheral glucose [1]. As metformin is eliminated from the proximal tubules without metabolization, it may accumulate in the body during renal insufficiency. Most metformin-induced toxicities are seen due to acute or chronic renal diseases, advanced liver problems, or simultaneously occurring acute diseases [2].

The reported side effects of metformin are frequently associated with the gastrointestinal tract. However, metformin-induced metabolic acidosis, which is a serious complication with a 
mortality rate of $50 \%$, may rarely occur. This complication is known to be associated with lactic acid elevation [3].

In this case report, we aimed to present the management of a patient who developed metabolic acidosis without lactic acidosis after metformin use in the intensive care unit.

\section{Case Presentation}

A 74-year-old male patient applied to the emergency department because of a femur fracture. He was admitted to the orthopedics and traumatology department with an operation plan. The comorbidities of the patient were type 2 diabetes mellitus, hypertension, chronic obstructive pulmonary disease, and benign prostatic hyperplasia. His medications were benidipine hydrochloride $8 \mathrm{mg}$, theophylline, tamsulosin $\mathrm{HCl} 0.4 \mathrm{mg}$, ipratropium bromide monohydrate + salbutamol sulfate $20 / 100 \mathrm{mcg}$, formoterol + budesonide $12 / 200 \mathrm{mcg}$, tiotropium bromide monohydrate $18 \mathrm{mcg}$, salbutamol inhaler $2.5 \mathrm{mg}$, and metformin $1000 \mathrm{mg}$ twice a day.

In the preoperative cardiology examination, the ejection fraction of the patient was evaluated as $60 \%$ and the left ventricular systolic function was normal. The hemoglobin level was 10.4 $\mathrm{g} / \mathrm{dL}$ in laboratory blood tests, and no other abnormality was detected. The metformin treatment was stopped 24 hours before the operation. In the operating room, the patient underwent spinal anesthesia with $10 \mathrm{mg}$ bupivacaine and $20 \mathrm{mcg}$ fentanyl. The surgery lasted for 90 minutes. The patient had $150 \mathrm{ml}$ hemorrhage and received saline $1000 \mathrm{ml}$ infusion with $500 \mathrm{ml}$ polyglycine. Hemodynamic values were stable throughout the operation and the patient was taken to the intensive care unit (ICU) for postoperative observation. The cardiac and respiratory examination of the patient was repeated in the ICU. Mild acidosis and hypoxia were detected in the admission arterial blood gas (ABG) examination (Table 1). The patient's albumin level was $2 \mathrm{~g} / \mathrm{dL}$ and human albumin $20 \%$ replacement treatment was applied. In the postoperative twelfth hour, metabolic acidosis with increased compensated anion clearance (30 $\mathrm{mEq} / \mathrm{L}$ ) was detected in the ABG analysis. The lactate level was within normal limits (Table 1). Urea and creatinine values were normal in the control blood tests and the hourly urine output of the patient was above $0.5 \mathrm{ml} / \mathrm{kg}$. The hourly blood glucose measurements were between 80 and $140 \mathrm{mg} / \mathrm{dL}$ within the first 12 hours. Since a hemoglobin level of $8.4 \mathrm{~g} / \mathrm{dL}$ was detected, the patient received a unit of erythrocyte suspension. Although a bolus dose of bicarbonate 8.4\% was administered intravenously, metabolic acidosis and the severe base deficit of the patient did not improve. So, intravenous bicarbonate infusion was initiated. As no additional reason for the persistent metabolic acidosis was detected, metformin was thought to be the cause of the metabolic situation of the patient.

At the postoperative twenty-fourth hour, the patients' metabolic acidosis was resolved and the bicarbonate infusion was terminated. Although there was high anion-gap (AG) metabolic acidosis, the lactate level of the patient was within normal ranges during this period. The patient was discharged from the ICU on the postoperative third day.

Table 1 shows the ABG values after admission to the ICU. 


\section{Cureus}

\begin{tabular}{|l|l|l|}
\hline Arterial blood gas analysis & Admission values & $\mathbf{1 2}^{\text {th }}$ hour values \\
\hline $\mathrm{pH}$ & 7.33 & 7.34 \\
$\mathrm{PaCO}_{2}(\mathrm{mmHg})$ & 39 & 21 \\
$\mathrm{PaO}_{2}(\mathrm{mmHg})$ & 55 & 98 \\
$\mathrm{SaO}_{2}$ & $89 \%$ & $97 \%$ \\
\hline $\mathrm{HCO}_{3}(\mathrm{mmol} / \mathrm{L})$ & 20.6 & 11.3 \\
\hline $\mathrm{Lactate}(\mathrm{mmol} / \mathrm{L})$ & 1.5 & 0.7 \\
\hline Chlorine $(\mathrm{mmol} / \mathrm{L})$ & 107.5 & 102.3 \\
\hline Sodium & 136 & 138 \\
\hline
\end{tabular}

TABLE 1: ABG values after admission to the ICU

ABG: arterial blood gas; ICU: intensive care unit

\section{Discussion}

Acid-base disorders are a commonly seen problem in the ICU. When the metabolic status of the patients is assessed in the ICU, it is seen that only $35 \%$ have a normal acid-base balance. Metabolic acidosis occurs either by the accumulation of a constant acid in the blood or by the loss of blood bases. In order to distinguish these reasons, the term AG was defined.

The AG value is the difference between the total major cations and anions in the plasma [4]. The most common cause of high AG metabolic acidosis is lactic acidosis. In addition, hypoxia, high doses of aspirin, methanol, ethylene glycol, paraldehyde, toluene, azotemic renal failure, ethanol, liver failure, ketoacids, fasting, and diabetes can also cause metabolic acidosis with high AG [5]. Despite the increased AG, the lactate levels of our patient ranged between 0.5 and $1.5 \mathrm{mmol} / \mathrm{L}$.

Our patient was slightly hypoxic at admission to the ICU, however, mild acidosis and hypoxia were detected in the admission arterial blood gas (ABG) examination. At the twelfth hour of intensive care, metabolic acidosis progressed despite heating and fluid replacement. So, we ruled out hypoxia from the etiology of metabolic acidosis. The use of metformin was considered the most likely cause of acidosis; hence, the patient did not have known aspirin or substance use or renal or hepatic insufficiency and had normal blood glucose levels. However, urinary output and urea creatinine levels were normal.

Although the most common side effects of metformin use are gastrointestinal problems, such as nausea and vomiting; hyperlactatemia and metabolic acidosis are rare but potentially serious side effects that can cause mortality [6]. These risks are thought to increase in cases of kidney or liver dysfunction, chronic heart or respiratory failure, sepsis and severe dehydration [7].

Metformin-associated lactic acidosis (MALA) is a rare but very dangerous complication of 
metformin use [8]. The presence of co-morbidities that may cause lactic acidosis is the most important factor that makes the differential diagnosis difficult. A meta-analysis by Inzucchi and colleagues reported a strong association between metformin and MALA development in patients with stable chronic kidney disease. MALA often develops in the case of concomitant acute disease, which can lead to acute renal failure [9].

However, so far, there is no case report regarding metabolic acidosis without lactic acidosis due to metformin use in the current literature. Despite the presence of type 2 diabetes in our patient, there was no kidney or liver failure and no increase in laboratory lactate levels.

In the case of MALA, the most important step in the treatment is ensuring adequate intravenous hydration. In addition, the use of targeting oxygen-sensing prolyl hydroxylase domain enzyme (PHD) has recently been proposed. Oyaizu-Toramaru and colleagues reported that the inhibition of PHD activates the transcription factor called hypoxia-inducible factor (HIF), which increases lactate excretion and gluconeogenesis in which lactate is used as a substrate [10]. Angioi et al. have reported that they applied continuous low-efficiency dialysis and bicarbonate to 28 patients with MALA and got positive results. We didn't consider dialysis in the treatment of our patient because lactic acid levels were within the normal ranges. However, bicarbonate infusion was applied to correct the resistant acidosis.

In our patient, the termination of metformin use, increasing hemoglobin levels above $10 \mathrm{~g} / \mathrm{dL}$ to improve oxygen delivery, and bicarbonate infusion for 24 hours successfully treated the metabolic status.

\section{Conclusions}

Metformin-induced metabolic acidosis with increased lactic acidosis is a well-known complication of metformin treatment, with a high mortality rate. In addition, clinicians should also consider that metformin-induced metabolic acidosis may develop without lactate elevation. In such cases, metformin treatment should be terminated and bicarbonate infusion should be initiated.

\section{Additional Information \\ Disclosures}

Human subjects: Consent was obtained by all participants in this study. Conflicts of interest: In compliance with the ICMJE uniform disclosure form, all authors declare the following: Payment/services info: All authors have declared that no financial support was received from any organization for the submitted work. Financial relationships: All authors have declared that they have no financial relationships at present or within the previous three years with any organizations that might have an interest in the submitted work. Other relationships: All authors have declared that there are no other relationships or activities that could appear to have influenced the submitted work.

\section{References}

1. Martin-Montalvo A, Mercken EM, Mitchell SJ, et al.: Metformin improves healthspan and lifespan in mice. Nat Commun. 2013, 4:2192. 10.1038/ncomms3192

2. Kopec KT, Kowalski MJ: Metformin-associated lactic acidosis (MALA): case files of the Einstein Medical Center Medical Toxicology Fellowship. J Med Toxicol. 2013, 9:61-66. 10.1007/s13181-012-0278-3

3. Chowdhury W, Lodhi MU, Syed IA, Ahmed U, Miller M, Rahim M: Metformin-induced lactic acidosis: a case study. Cureus. 2018, 4:2152. 10.7759/cureus.2152

4. Moe OW, Fuster D: Clinical acid-base pathophysiology: disorders of plasma anion gap . Best 


\section{Cureus}

Pract Res Clin Endocrinol Metab. 2003, 17:559-574. 10.1016/S1521-690X(03)00054-X

5. Scheen AJ: Metformin and lactic acidosis. Acta Clin Belg. 2011, 66:329-331.

6. Timbrell S, Wilbourn G, Harper J, Liddle A: Lactic acidosis secondary to metformin overdose: a case report. J Med Case Rep. 2012, 6:230.

7. Salpeter SR, Greyber E, Pasternak GA, Salpeter EE: Risk of fatal and nonfatal lactic acidosis with metformin use in type 2 diabetes mellitus: systematic review and meta-analysis. Arch Intern Med. 2003, 163:2594-2602. 10.1001/archinte.163.21.2594

8. Stades AM, Heikens JT, Erkelens DW, Holleman F, Hoekstra JB: Metformin and lactic acidosis: cause or coincidence? A review of case reports. J Intern Med. 2004, 255:179-187. 10.1046/j.1365-2796.2003.01271.x

9. Inzucchi SE, Lipska KJ, Mayo H, Bailey CJ, McGuire DK: Metformin in patients with type 2 diabetes and kidney disease. A systematic review. JAMA. 2014, 24:2668-2675. 10.1001/jama.2014.15298

10. Oyaizu-Toramaru T, Suhara T, Hayakawa N, et al.: Targeting oxygen-sensing prolyl hydroxylase for metformin-associated lactic acidosis treatment. Mol Cell Biol. 2017, 37:00248. 10.1128/MCB.00248-17 